\title{
El «regreso de Dios» a la política: las religiones «públicas»
}

\author{
Manuel M. ${ }^{a}$ Urrutia León \\ Profesor de Sociología del Hecho Religioso \\ Universidad de Deusto
}

Recibido: 05.10 .06

Aceptado: 10.10 .06

\begin{abstract}
Resumen: Este artículo se acerca al fenómeno de la irrupción de las religiones en el ámbito público, que se produce a partir de finales de los años 1970 a lo largo del mundo. El objetivo de este trabajo es, por un lado, desarrollar los dos modelos típico-ideales de «religiones públicas» posibles, según sea la postura que la religión adopte respecto a la democracia y a la laicidad; y, por otro lado, replantear el paradigma de la secularización, que defendía la privatización de la religión, para que se haga cargo de aquella presencia pública de las religiones que sea legítima y aceptable para una sociedad democrática.
\end{abstract}

Palabras clave: Religiones públicas. Política. Secularización. Democracia.

Abstract: This article focuses on the irruption of religion in the public sphere that takes place at the end of the XX century 70 s all around the world. The main aim of this work is, on the one hand, to develop the two typical-ideal models of «public religions» possible, according to the position that religion adopts concerning democracy and laicism and on the other hand, to rethink the paradigm of secularization that defended the privatization of religion so it would be able to take into account a public presence of religions that could be considered legitimate and acceptable to a democratic society.

Key words: Public religions. Politics. Secularization. Democracy.

Sumario: 1. Introducción.-2. La irrupción de las religiones en el ámbito público a partir de finales de los años 1970.—3. Religiones públicas a la «reconquista del mundo».-4. Un dilema: ¿ «retorno de la religión» o fracaso político y social de la modernización?-5. Religiones públicas legítimas en una sociedad laica.-6. Bibliografía citada.

\section{Introducción}

A partir de finales de los años 1970 y durante la década de los 1980, algo empezó a cambiar a lo largo del mundo globalizado. Inesperadamente, y contraviniendo uno de los elementos fundamentales del paradigma de la secularización dominante en el pensamiento occidental, que auguraba que las religiones se refugiarían en la esfera privada -perdiendo toda relevancia pública en las sociedades modernas y, como producto de la modernización, a medio plazo también en el resto del mundo-, las religiones rea- 
parecieron con fuerza en el ámbito público y político en muchos lugares del mundo.

El presente artículo se acerca a ese momento histórico, y a través del desarrollo de los dos modelos tipo-ideales de «religiones públicas» posibles, según sea la postura que adopte la religión respecto a la democracia y la laicidad, tratará de replantear de manera adecuada el paradigma de la secularización para que se haga cargo de aquella presencia pública de las religiones que sea legítima y aceptable para una sociedad democrática.

\section{La irrupción de las religiones en el ámbito público a partir de finales de los años 1970}

«Dios vuelve a la política» leía, al comenzar a escribir estas líneas en el verano de 2006, en la portada de la edición española de la revista Foreign Policy, título que contrasta vivamente, lo recordaban los autores del artículo que daba pie a dicha expresión, con la ya célebre portada de la prestigiosa revista Time que, en abril de 1966, se preguntaba: «¿Dios está muerto? ${ }^{1}$ ». Lo sugerente de este titular, aunque en absoluto novedoso, es la utilización del concepto de «vuelta»-también se habla de «regreso» o de «retorno»-; conceptos que se aplican a la religión en general, y en este caso a la vuelta de la religión a la esfera pública en particular, y que quieren enfatizar el importante giro que se habría producido en las últimas décadas frente a la situación anterior.

En efecto, desde la aparición misma del «paradigma de la secularización $»^{2}$, a finales de los años 1960, y acompañando a su consolidación posterior, éste será cuestionado por varios acontecimientos históricos, inicialmente de dos tipos diferentes.

En un primer momento, a principios de los años 1970, las discusiones en torno a la problemática de la secularización se centraron en la emergencia de los llamados desde entonces «Nuevos Movimientos Religiosos»; pero poco después, a finales de la misma década, el centro de las miradas se desplazó al fenómeno que nos ocupa, a un hecho aún más sorprendente e imprevisto si cabe que el anterior para la mayoría de los teóricos de la secularización: la importante irrupción de las religiones en la esfera pública en muchos lugares del mundo. Como escribía William Swatos en un libro de finales de los años 1980:

\footnotetext{
1 «Dios vuelve a la política». Foreign Policy. Política, economía e ideas globales. Edición española, n. ${ }^{\circ}$ 16, agosto-septiembre 2006. El artículo «Por qué Dios está ganando» está firmado por Timothy Samuel SHAH y Monica DUFFY y ocupa las páginas 22 a 28.

${ }^{2}$ Para todo lo referente al «paradigma de la secularización» (sus antecedentes, sus contenidos, sus presupuestos e hipótesis fundamentales, sus defensores, etc.), véase mi artículo: Urrutia, 2005.
} 
«Sería difícil pensar en un fenómeno que cogió más por sorpresa a los estudiosos de la religión occidentales que el resurgimiento por todo el mundo de la religión -ireligión política nada menos!- ocurrido con visibilidad creciente mientras transcurrían los años 1970» (SwATOS, 1989: 1).

Igualmente, Bruce Lawrence sentenciaba por esas mismas fechas: «Nadie estaba preparado para la vuelta de la religión a la política global en los 1980», y añadía, refiriéndose al acontecimiento que acabaría por vencer las resistencias de algunos teóricos escépticos ante la importancia y magnitud del fenómeno: «el fundamentalismo islámico era la respuesta a la pregunta planteada en Irán: ¿la religión cuenta aún en la arena pública?» (LAWRENCE, 1989: XII y XIII).

El fenómeno, que afectaba también a las sociedades modernas occidentales, cogió a todo el mundo por sorpresa, pues si existía una convicción firme y prácticamente unánime entre los defensores del «paradigma de la secularización» era que las religiones tendían a privatizarse. Que la religión tendía a restringirse, en palabras de Berger, a la «esfera privada de la vida social cotidiana», de tal forma que «los valores pertenecientes a la religiosidad privada son específicamente irrelevantes para los contextos institucionales que sobrepasen la esfera privada» (BERGER, 1999/1967: 192). En este sentido Thomas Luckmann, que fue entre los sostenedores del «paradigma de la secularización» quien seguramente más extensa y agudamente se refirió al paso de la religión desde la esfera pública a la privada, titularía un importante libro suyo, significativamente, La religión invisible. Para él, la «nueva forma social» emergente de la religiosidad era una forma radicalmente subjetiva de religión que, frente a la tradicional «religiosidad orientada a la iglesia», plenamente «visible», consiste en la posibilidad y aún en la necesidad de que el individuo autónomo se construya por sí mismo un sistema privado más o menos articulado de significado «último» (LUCKMANN, 1973/1967: 116), con lo que este tipo de religiosidad se vuelve «invisible». Para concluir, al final de su obra, señalando cómo el proceso de radical subjetivización de la religión que había descrito le parecía prácticamente irreversible: «Es improbable que el indicio que hemos intentado describir sea reversible, aun admitiendo que tal reversibilidad se considere deseable» (Ibidem: 129).

Pues bien, precisamente por su carácter totalmente inesperado, el hecho de que a finales de los años 1970 las religiones, a lo largo de todo el mundo, penetrasen de forma masiva en la esfera pública, sorprendió poderosamente a los teóricos de la secularización, que se verían obligados a partir de entonces a replantearse sus presupuestos, lo que acabaría además por introducir importantes cambios en la percepción social del hecho religioso.

«En muchas partes del mundo -África, Filipinas, Irán, Líbano, Nicaragua, Brasil, EE.UU.- las relaciones entre las instituciones religiosas y los poderes dominantes han experimentado cambios dramáticos [...]. 
Estos desarrollos [...] plantean cambios a las maneras en que pensamos acerca del lugar público de la religión en el mundo contemporáneo. Ellos nos han obligado a cuestionarnos si nuestras teorías convencionales son adecuadas para la tarea o si necesitamos dirigirnos hacia nuevas interpretaciones» (WUTHNOW, 1992: 131).

Como escribirá Casanova, a partir de los años 1980 la religión «se hizo pública» en un doble sentido. Por una parte, porque penetró en la esfera pública, moral y política, de las sociedades; y por otra parte, porque ganó publicidad (CASANOVA, 2000: 15), apareciendo reiteradamente en los medios de comunicación y, a través de su influencia, en la opinión pública en general logrando que el fenómeno de la presunta «vuelta de lo religioso» comenzara a ponerse de moda. Y lo que es más importante, haciendo que la investigación sobre el hecho religioso pasase a un primer plano en el ámbito de las ciencias sociales. No sólo en la sociología de la religión, que abandona su situación casi marginal anterior y cobra inusitada importancia, sino que el estudio del «factor religioso» pasa a ocupar una posición relevante en los ámbitos de investigación de la ciencia política, la filosofía moral, la antropología, las relaciones internacionales, etc., entrando a formar parte al mismo tiempo de las agendas de los políticos y de las organizaciones internacionales, e influyendo en amplios círculos de la sociedad civil.

Nos encontramos ante un fenómeno de gran relevancia, mucho más importante que el de los «Nuevos Movimientos Religiosos», tanto numéricamente, por la gran cantidad de personas involucradas, como sobre todo por la influencia social, política, moral, cultural, etc., de éste. Y que afectando a las dos subtesis fundamentales de la secularización, la tesis de la decadencia de la religión y la tesis de la privatización de la religión, sobre todo va directamente en contra de esta última, pues implica la «desprivatización» de la religión en el mundo moderno. En palabras de Casanova, el «hecho de que las tradiciones religiosas de todo el mundo se niegan a aceptar el papel marginal y privatizado que les han reservado las teorías de la modernidad y las teorías de la secularización» (CASANOVA, 2000: 18). Fenómeno para el que se va a acuñar un nuevo concepto, el de «religiones públicas», frente a las religiones privadas o privatizadas; pudiendo existir dos formas fundamentales, ideal-típicas en sentido weberiano, de religiones públicas en función de la postura que adopten las religiones frente a la democracia moderna: 1) aquellas que se oponen frontalmente a la modernidad secularizada; 2) o aquellas religiones públicas «viables» y «legítimas» en la medida en que respeten y potencien la sociedad democrática y laica.

\section{Religiones públicas a la «reconquista del mundo»}

La aportación de Gilles Kepel, uno de los precursores en el estudio de la irrupción de las religiones en la esfera pública, nos servirá para ejemplificar 
el primero de los modelos de religiones públicas desde un punto de vista histórico. Kepel, en un libro ya clásico, habló de «la revancha de Dios» para referirse a un conjunto de movimientos religiosos (cristianos, judíos y musulmanes) que, emergiendo a finales de los años 1970, se lanzaban a la «reconquista del mundo». Más allá del eco mediático que el libro adquirió, debido en parte a la metáfora sugerente e impactante de su título, nos encontramos ante una valiosa aproximación teórica, sin duda una de las más originales, a un fenómeno que con el tiempo iría cobrando importancia creciente.

«Un nuevo discurso religioso toma forma, no para adaptarse a los valores seculares sino para devolver el fundamento sacro a la organización de la sociedad, cambiándola si es necesario. Este discurso, a través de sus múltiples expresiones, propone la superación de una modernidad fallida a la que atribuye los fracasos y las frustraciones provenientes del alejamiento de Dios [...]. En quince años este fenómeno ha adquirido dimensión universal: surgió de civilizaciones que difieren entre sí tanto por su origen cultural como por su grado de desarrollo. Pero, sobre todo, se desplegó como reacción a una «crisis» de la sociedad cuyas causas profundas dice haber identificado, por debajo de los síntomas económicos, políticos o culturales a través de los cuales se manifiesta [...].

Más que combatir una ética laica que consideran inexistente, piensan que la modernidad producida por una razón sin Dios no ha sabido, en definitiva, engendrar valores: al atascar los mecanismos de solidaridad generados por el Estado-providencia, la crisis de los años setenta dejó al desnudo angustias y miserias humanas sin precedente. A los ojos de los nuevos militantes religiosos, esa crisis revela la vacuidad de las seculares utopías liberal o marxista, cuya traducción concreta es en Occidente el egoísmo consumista, y en los países socialistas y el Tercer Mundo la gestión represiva de la penuria, en un marco de olvido de la sociedad de los hombres» (KEPEL, 1995a: 14 y 18).

Valga esta larga cita a modo de resumen del significado de estos movimientos, así como del contexto de crisis social al que remiten.

La originalidad de la perspectiva de Kepel, y por la que el libro sería además criticado, radicaba en el establecimiento de una perspectiva comparativa entre las tres grandes «religiones del Libro» (incluso aludía a que se encontraban rasgos semejantes también, por ejemplo, en ciertos movimientos hinduistas y sintoístas), cuando algunos críticos sostenían que hablar de «revancha de Dios», sobre todo desde la perspectiva del «peligro» potencial de tales movimientos, no tenía sentido más que en su referencia al mundo musulmán (KEPEL, 1995b: 9).

Kepel, más allá de las diferencias evidentes, creía encontrar «asombrosas similitudes» entre ciertos movimientos religiosos católicos, judíos o cristianos y los movimientos islámicos que había estudiado previamente. Pero es que, además, la aparición casi simultánea de estos grupos a partir de 1975 
(con el detonante de la crisis económica mundial de 1973-1974), no le parecía que podía deberse al azar y defendía, por tanto, su estudio como un fenómeno global, como el testimonio de una enfermedad social profunda, enmarcándose todos ellos en el contexto de descalificación global de la modernidad que se inició en esa época.

Tales movimientos coinciden en su diagnóstico de los males de la modernidad y en el tratamiento que consideran adecuado para superarlos. Parten del cuestionamiento de los fundamentos sociales del orden cultural de la modernidad y más específicamente de una impugnación radical de las bases de la modernidad laica cuyo origen remite a la ilustración: «en la orgullosa emancipación de la razón respecto de la fe ven la causa fundamental de los males del siglo XX» (KePEL, 1995a: 266). Luego el remedio está en la «resacralización» de la sociedad, en su transformación para dotarla de un sentido total y de los valores aportados por la religión correspondiente.

Pero esta «lucha por la hegemonía sobre el sentido» (1995b: 15) no se produce sólo en el exterior a la propia tradición religiosa, en la sociedad circundante, sino que es una lucha que tiene su origen en el interior de la tradición religiosa misma, de una manera específica y radical. Quizás nos encontremos con uno de los rasgos decisivos de estos movimientos: la utilización del material religioso de la tradición correspondiente, oponiéndose muchas veces al discurso dominante de la «religión oficial», de cara a la intervención política del movimiento. Se produce la elaboración más o menos explícita de un proyecto de reconstrucción del mundo que encuentra en los textos sagrados respectivos los fundamentos de la sociedad futura. Fred Halliday, quien comparte básicamente la aportación de Kepel en este punto y refiriéndose más explícitamente al fundamentalismo, introduce un matiz que nos puede ayudar a comprender mejor lo que está en juego. Halliday distingue entre dos elementos que en el fundamentalismo están ligados de forma contingente. «Uno lo constituye la invocación a un retorno a los textos sagrados, leídos de modo literal, y el otro la apelación a que estas doctrinas se apliquen a la vida social y política» (HALLIDAY, 1994: 38). Dos formas de interpretación de los textos que llamará escritural y contingente respectivamente, siendo esta última la que tiende a predominar. «Lo que resulta importante es que, en circunstancias modernas, son los deseos contemporáneos, no una cierta interpretación inmanente verdadera, los que determinan el uso que se hace de esos textos» (Ibidem: $45^{3}$ ). Tal interpretación contingente subordinada al objetivo prioritario de la transformación radical del mundo es, al mismo

\footnotetext{
${ }^{3}$ Como intenta demostrar en el caso iraní, el curso de su revolución se explica mucho mejor no en forma escritural sino de política pragmática, y concretamente la teoría de Jomeini del «gobierno islámico», que acabaría por marcar dicho rumbo de forma decisiva, no es (puramente) teológica sino más bien producto de una utilización ideológica «para justificar la meta mundana y universal de mantener el poder del Estado» (HALLIDAY, 1994: 47).
} 
tiempo, uno de los rasgos que convierte a estos movimientos en plenamente «modernos».

Utilizándose para este fin de transformación global de la sociedad, volvemos a Kepel, dos tipos de estrategias posibles en función de las circunstancias concretas: una resacralización «desde arriba», a través de la toma del poder, o una resacralización «desde abajo», estableciendo redes de comunidades que practiquen una forma de vida total que rompa radicalmente con la sociedad circundante.

\section{Movimientos de «resacralización» a finales de los 1970, según Gilles KEPEL}

Judíos. En 1977, por primera vez en la historia del Estado de Israel, los laboristas no pueden formar gobierno y se encarga de ello Menahen Begin. Y coincidiendo con esta pérdida de hegemonía del sionismo laico, movimientos religiosos de muy distinto signo entran en la escena política y en el gobierno (y el movimiento sionista religioso comienza la implantación de colonos en los territorios ocupados bajo la invocación del antiguo pacto entre Dios y el pueblo elegido...).

Musulmanes. A partir de la década de 1970 resurge el Islam en su forma política (de Malasia a Senegal, las Repúblicas Soviéticas musulmanas o las periferias urbanas europeas) y comienza un amplio movimiento de reislamización. Sobresale el triunfo de la revolución del Ayatolá Jomeini, en 1979, que instaura la República Islámica en Irán.

Cristianos católicos. En 1978, el ascenso al papado de Juan Pablo II provocará cambios importantes en la línea del catolicismo tras el Concilio Vaticano II; 1979 es el año de la irrupción del Sindicato Solidaridad en Polonia, convirtiendo al país en el «laboratorio» de la estrategia papal de la recristianización de Europa. Durante los años 1980 ciertos grupos religiosos que convergen con esta estrategia serán potenciados: grupos carismáticos; el movimiento Comunión y Liberación, etc.

Cristianos protestantes. En los EE.UU. y en el ámbito del cristianismo protestante juegan un papel relevante los movimientos de tipo fundamentalista y evangélico en su intento de recristianizar la sociedad americana (p. ej., el fenómeno de la Mayoría Moral, que surge en 1979 e interviene activamente en la elección del Presidente Reagan en 1980 y en 1984). 


\section{Estrategias de resacralización}

En su intento de resacralizar la sociedad estos movimientos utilizan dos tipos de estrategias, dependiendo de las circunstancias y

posibilidades concretas:

(1) Resacralización «desde abajo»: a través de la constitución de redes de comunidades de verdaderos creyentes que pongan cotidianamente en práctica los preceptos del dogma religioso. «Pietismo» que trata de transformar el sistema sin violencia, royéndolo desde dentro, rompiendo radicalmente con la sociedad circundante.

(2) Resacralización «desde arriba»: estrategia de ruptura con el orden establecido, en este caso a través de la conquista del poder y la transformación revolucionaria de la sociedad.

Elaboración propia a partir del texto de KEPEL (1995a).

Obviamente, más allá de esta coincidencia de fondo en el rechazo de la laicidad, los contenidos doctrinales y los proyectos sociales que se derivan de ellos son profundamente divergentes, pudiendo convertirse en antagónicos. Sobre todo son significativas las diferencias en las relaciones de los distintos movimientos con el Estado, la Ley y los límites democráticos (KEPEL, 1995a: 272-ss.). Lo que depende no sólo de sus distintas doctrinas religiosas, y su interpretación «pragmática», sino también del contexto social y político en que se ubican. Frente al «monismo» del Islam y del judaísmo, para el que la Ley revelada por Dios es el principio exclusivo de la organización social, lo que en los movimientos más radicales conduce a un rechazo de la noción misma de democracia, el «dualismo» cristiano representado por la frase evangélica «Dad al César lo que es del César y a Dios lo que es de Dios» impone una «limitación democrática» que incide sobre el contenido de esos movimientos, obligándoles a aceptar la democracia e impidiéndoles utilizar la violencia. Limitación democrática que «también existe para los movimientos de rejudaización y reislamización 'desde abajo' que se desarrollan entre los judíos de la diáspora y los musulmanes emigrados a Europa» (Ibidem: 299, nota 231). Entre estos grupos la lucha se centra en lograr que se reconozca a su identidad y a sus valores religiosos un espacio mayor en la vida pública, en la reducción del espacio público del laicismo.

En definitiva, nos encontramos ante un fenómeno completamente nuevo: el retorno de las religiones al primer plano de la organización política y social, que «se inscribe en el enorme cambio registrado en la organización del mundo a partir de los años setenta» (basado en los medios de comunicación de masas y alimentado por las crecientes bolsas de marginación y la desaparición de la bipolaridad capitalismo-comunismo). Con el paso del 
tiempo todo se iba complicando más aún, a marchas forzadas, por la aceleración de un fenómeno que en esos años subyacía ya a los principales análisis del fenómeno de la irrupción de las religiones en la esfera pública, y singularmente como vemos en la lógica del análisis comparativo de Kepel, como es el de la globalización, pero que posteriormente -la caída del muro de Berlín en 1989 puede tomarse como punto simbólico de inflexión- se haría omnipresente condicionando toda la realidad a nivel mundial. Globalización que, para algunos intérpretes, parece favorecer la presencia de las religiones políticas. El propio Kepel sentenciará en una entrevista posterior: «Asistimos al retorno de la religión como factor en las relaciones internacionales» (1994: 3). O, por las mismas fechas, Halliday, y refiriéndose más específicamente a los movimientos fundamentalistas, escribía que todo parecía indicar que «pueden permanecer largo tiempo entre nosotros» (1994: 48). ${ }^{4}$

\section{Un dilema: ¿»retorno de la religión» o fracaso político y social de la modernización?}

Con el avance de la globalización el panorama internacional cambia de forma acelerada y con él todas las categorías del pensamiento recibidas para hacernos cargo de él parecen tambalearse, a lo que no va a ser ajena la idea de la «secularización» que iba asociada, no lo olvidemos, a la modernización social que ahora la globalización va extendiendo por doquier.

Con lo que el dilema que ahora se nos plantea es el siguiente:

(1) ¿Nos encontramos realmente ante un «retorno de la religión» y más en concreto al ámbito público de las sociedades, que la globalización parece propiciar, y por consiguiente ante el desmentido más rotundo del paradigma de la secularización, como piensan algunos?

«La creencia de que los brotes de religión politizada son desvíos temporales en el camino hacia la secularización era plausible en 1976, en 1986 o incluso en 1996. Hoy día, este argumento es insostenible. Como marco para explicar y predecir el curso de la política global, el secularis-

\footnotetext{
${ }^{4}$ Jacques Sutter sostuvo que La revancha de Dios se había beneficiado del «eco mediático» que tiende a amplificar de manera artificial ese tipo de fenómenos. Y criticaba a Kepel por haber sobredimensionado el fenómeno, que no tenía además una significación meramente «religiosa», por lo que, a su juicio, era necesario relativizar la importancia de los movimientos estudiados en el seno de las tradiciones religiosas y sobre todo en la sociedad en su conjunto (SUTTER, 1991). Visto en perspectiva creo que el planteamiento de Kepel (que sería complementado por gran cantidad de estudios empíricos), no incurría en tales «excesos» y se ha demostrado fértil como aproximación a la génesis histórica de un hecho relevante y de enorme actualidad.
} 
mo es cada vez menos sólido. Dios está ganando la batalla en la política global. Y la modernización, la democratización y la globalización solamente le han hecho más fuerte» (SHAH y DUFFY, 2006: 28).

Lo que nos reenvía a otro problema decisivo estrechamente relacionado con éste. La interpretación «contingente» (Halliday) de las doctrinas religiosas para aplicarlas a la vida social y política, que efectúan la mayoría de estos movimientos, nos recuerda que casi nunca cabe hacer una interpretación puramente «religiosa» de éstos; que, como en cualquier otra realidad de las que se ocupan las ciencias humanas y sociales, hay varios factores que actúan a la vez (religioso, político, ideológico, económico, etc.), que habría que tratar de ponderar debidamente en cada caso concreto y ver en qué medida hablamos de una renovada presencia de lo religioso o más bien de una instrumentalización de un factor (lo religioso) que demuestra, eso sí, una gran capacidad de movilización (como lo étnico, lo comunitario, etc.) La extensión de la instrumentalización de lo religioso por intereses políticos, económicos, estratégicos, etc., en muchos de los lugares donde aparece la religión, cuestionaría la alternativa planteada en este primer polo del dilema y reforzaría el otro.

«¿Hablando de estos movimientos, de qué se habla exactamente? ¿De movimientos primaria y fundamentalmente religiosos, que instrumentalizan lo político con el objetivo de la resacralización del espacio público? ¿De movimientos primaria y fundamentalmente políticos, que instrumentalizan lo religioso con el objetivo de la conquista del poder (o de la legitimación del poder adquirido)? ¿O de movimientos simultáneamente políticos y religiosos, que apuntan al mismo tiempo al poder y a la resacralización del espacio público y cuya característica sería por lo tanto que no concebirían el poder más que en y por referencia a lo religioso y lo religioso más que en y por referencia al poder? Sí, pero entonces ¿cuál sería, incluso sin tener en cuenta todos los fenómenos, potenciales o reales, de manipulación, la jerarquización de los objetivos pretendidos en el interior mismo de la confusión inducida por esta doble referencia? [...].

Se podría [...] sostener la idea de que estos movimientos [...] lejos de manifestar un "retorno de lo religioso", atestiguan su desaparición, señalando un vacío, un déficit de la política en el momento presente, masivo y cruel, que carecería incluso de términos políticos que permitirían expresarla. De ahí el recurso a lo religioso, como registro del discurso, como lenguaje» (MicHEL, 1994: 107-108).

Con lo que el segundo polo del dilema podría plantearse así:

(2) ¿Más que un «retorno de la religión» no sucederá, como piensan otros intérpretes, como es el caso de Michel, que la politización de la religión responde a una fase transitoria de la historia, propiciada por el fracaso de la modernización o por una modernización desordenada y desarraigadora de las sociedades a consecuencia de la intensa y profundamente desigual 
globalización en curso, y en la medida en que las sociedades se vayan modernizando y democratizando de forma adecuada habrán de secularizarse necesariamente al menos en este sentido de la privatización de la religión?

En esta dirección apunta, por ejemplo, la excelente obra de Marcel Gauchet, El desencantamiento del mundo. Una historia política de la religión (1985), que desde su perspectiva de una «historia política» de la religión y ampliando el fértil planteamiento weberiano, desarrolla su tesis del cristianismo como la religión de la «salida de la religión». El autor, en una reciente entrevista (2005b), enfrentándose con el dilema que planteamos, expresaba lo siguiente:

«Se habla de "retorno de lo religioso" desde hace veinticinco años, de hecho desde la revolución islámica en Irán, en 1979. [...] lo que está en juego, desde hace un cuarto de siglo o algo más, detrás de esta agitación superficial es, en contra de las apariencias, una etapa crucial de la salida de la religión; una etapa que amplía, intensifica y acelera el fenómeno. Lejos de «retornar», la organización religiosa del mundo se desvanece. La salida de la religión alcanza de lleno lugares a los que hasta ahora llegaba de manera remota. Precisamente se despliegan y prosperan como reacción a esta descomposición, esforzándose por recuperar y reconstituir lo que desaparece $[\ldots]$.

La salida de la religión es la salida de la estructuración religiosa de las sociedades; un proceso que duró siglos en Occidente, y en donde está a punto de acabar. Un proceso que, gracias a la globalización, alcanza hoy al conjunto de las civilizaciones y tradiciones del planeta, provocando los sobresaltos fundamentalistas que a los occidentales, para los que la estructuración religiosa no quiere decir gran cosa, les cuesta tanto comprender» (GAUCHET, 2005b: 293 y 294).

La concepción de Gauchet de la «salida de la religión»-no dejemos engañarnos por expresiones como fin o final de la religión que el autor utiliza igualmente para referirse al mismo fenómeno-, se asemeja plenamente a la hipótesis de la «privatización» de la religión y en absoluto debe interpretarse en el sentido de una supuesta «desaparición de la religión», que algunos críticos del «paradigma de la secularización», de forma totalmente errónea, equiparan al proceso de secularización como tal. Nada más falso. Ya en los sociólogos clásicos, Durkheim y Weber, fundadores de la sociología de la religión, y mucho más explícitamente aún en los sostenedores del «paradigma de la secularización», se defiende justamente lo contrario: que la «secularización», en sus distintas modalidades, en ningún caso parece implicar que la religión fuera a desaparecer (URRUTIA, 2005: 175-176). Para Gauchet el fin de la religión significa el final de su función práctica tradicional, de su función política y de aglutinante del cuerpo social, es decir, que la religión ya no va a volver a organizar completamente el campo huma- 
no y social más, como lo hizo históricamente. Luego nada de muerte de los dioses, ni desaparición de los creyentes y de sus iglesias y, por otro lado, es fácil constatar además la aparición de equivalentes religiosos en muchos ámbitos profanos. Incluso más aún, piensa Gauchet, es más que verosímil concebir la existencia de una experiencia de tipo religioso como un núcleo antropológico irreductible en el ser humano. Por lo que las creencias religiosas, que arraigan en la subjetividad de la conciencia, seguirán jugando un importante papel en la sociedad, eso sí, una sociedad organizada totalmente al margen de la religión, una sociedad que funciona «como si Dios no existiera».

«Incluso suponiendo la edad de las religiones definitivamente cerrada hay que convencerse de que, entre religiosidad privada y sustitutos de la experiencia religiosa, probablemente nunca terminaremos con lo religioso [...]. La discontinuidad en el orden de la función social se ha producido ya esencialmente. En cambio, la continuidad en el registro de la experiencia íntima no ha terminado de reservarnos sorpresas. [...] estamos ante uno de los grandes focos futuros de la invención cultural»(GAUCHET, 2005a: 283).

Está claro que el dilema planteado sólo podrá ser respondido en el futuro y no sabemos por cuánto tiempo seguirán proponiéndose falsas alternativas, como las religiones políticas, a nuestra globalización desbocada. Pero también es cierto que, como insinuábamos más arriba, si lográramos superar las consecuencias más destructivas del profundamente desigual desarrollo de la economía mundial, y si la globalización fuera poco a poco potenciando una modernización que consolide la democracia pluralista y los derechos humanos a lo largo del mundo, ello no podrá hacerse sin fortalecer a un mismo tiempo su base necesaria, la laicidad -si bien que revisada para adaptarse a los nuevos desafíos globales, como la aparición y profundización del multiculturalismo en todas las sociedades, etc.-, y por lo tanto una cierta «privatización» de la religión.

Pero, aunque parezca paradójico, voy a defender a continuación cómo las religiones pueden contribuir a la potenciación de esos valores universales como son los derechos humanos y la democracia, y para ello no pueden resignarse a una privatización total, sino que han de ser «públicas» al menos en un cierto sentido.

\section{Religiones públicas legítimas en una sociedad laica}

«... la génesis del hecho democrático sólo puede entenderse históricamente, según nuestro punto de vista, como el establecimiento de una forma subjetiva de funcionamiento social. El advenimiento de la democracia es el paso de la sociedad de religión, es decir, de la sociedad sujeta a 
Otro, a la sociedad sujeta a ella misma, en tanto que sociedad estructurada fuera de la religión» (GAUCHET, 2005a: 245).

Si convenimos con Gauchet que una sociedad democrática es una «sociedad sujeta a sí misma», entonces cobra enorme importancia el concepto de laicidad, y más aún su adecuada plasmación en la realidad, pues supone convertir a la ciudadanía en el centro de la vida pública frente a cualquier tipo de identidad societaria que se pretenda global, no ya sólo religiosa, sino étnica, ideológica, comunitaria, etc.

Ahora bien, ¿las sociedades modernas, laicas, sustentadas en la democracia y el respeto a los derechos humanos, exigen necesariamente que las religiones se sometan a una subjetivización o privatización total? ¿O cabría algún tipo de «religión pública», o de expresión «pública» de la religión, no sólo escrupulosamente respetuosa con la sociedad laica, sino incluso potenciadora de ésta? Creo que en el intento de responder fundadamente a esta pregunta se encuentra una de las aportaciones más valiosas del planteamiento de José Casanova, que representa el segundo de los modelos tipo-ideales propuestos.

Casanova cree, lo que comparto plenamente, que el fenómeno de la desprivatización de la religión vivido a partir de los años 1980 exige un replanteamiento crítico de las «teorías de la secularización», pero en ningún caso su abandono. Y que para ello es necesario diferenciar analíticamente, para poder evaluar por separado, las que considera las tres premisas principales del «paradigma de la secularización»: 1) la tesis central o tesis de la diferenciación (que se identifica con el proceso de secularización como tal), es decir, «la conceptualización del proceso de modernización de la sociedad como un proceso de diferenciación y emancipación estructural de las esferas seculares -principalmente el Estado, la economía y la ciencia- respecto a la esfera religiosa»(CASANOVA, 2000: 36), de la que se han hecho derivar dos subtesis que supuestamente explicarían lo que le ocurriría a la religión como resultado de este proceso; 2) la tesis de la decadencia de la religión; 3 ) la tesis de la privatización de la religión en el mundo moderno.

Lo que sucede es que sólo la primera, la diferenciación funcional y estructural de las sociedades, es realmente necesaria, se trata de una «tendencia estructural moderna», por lo que constituye el núcleo válido, tanto a nivel empírico como normativo, de las «teorías de la secularización». Por ello, la separación entre la iglesia (religión) y el Estado (política), y la libertad de creencia son una condición necesaria de la modernización social en el sentido aludido. Por lo que las religiones políticas (o cualquier visión totalizadora del mundo) son rechazables no ya sólo desde un punto de vista valorativo sino igualmente empírico.

Pero de aquí no se sigue que cualquier expresión pública de la religión ponga inevitablemente en peligro la diferenciación funcional moderna: 
«puede haber y hay religiones públicas en el mundo moderno que no necesitan poner en peligro ni las libertades individuales modernas ni las estructuras diferenciadas modernas» (Ibidem: 290). Y si es así no se haría necesaria su reducción «absoluta» a lo privado.

La privatización es una «tendencia histórica» que, eso sí, se ha convertido en dominante debido, además de a la influencia de la propia estructura social diferenciada, a ciertas bases históricas particulares, occidentales y etnocéntricas, en las que se desarrollaron las «teorías de la secularización», y por lo que concierne a la ideología muy especialmente al dominio de las concepciones liberales de la política y las esferas públicas que tienden a prescribir la privatización de la religión, su despolitización, como presunta garantía de la separación estructural y de las libertades individuales.

Ahora bien, el liberalismo confunde tres niveles diferentes en el ámbito de la esfera pública que conviene distinguir analíticamente: Estado, sociedad política y sociedad civil. Obviamente, desde el punto de vista normativo del que partimos, la presencia pública de las religiones no cabe ni en el ámbito del Estado (iglesias oficiales, teocracias, etc.), que impiden la separación iglesia/Estado y la libertad religiosa, absolutamente esenciales; ni de la sociedad política (movimientos sociales o políticos confesionales), sino tan sólo en el de la sociedad civil.

¿Con qué objetivos? Una iglesia «orientada hacia la sociedad civil» entraría en la esfera pública «para defender la institucionalización de los derechos universales modernos, la creación de una esfera pública moderna y el establecimiento de regímenes democráticos» (Ibidem: 297), luego en ningún caso sus propias prerrogativas o presuntos derechos. Y en este ámbito podemos señalar su posible contribución -en la que coincidiría con otras críticas normativas similares al liberalismo de teóricos críticos, republicanos o feministas-, a la creación de una verdadera «esfera pública moderna», frente a la concepción liberal de las esferas públicas de la economía y de la política como amorales y frente al excesivamente riguroso trazado de fronteras que realiza el liberalismo. Las fronteras entre público/privado, moral/legal, religión/secular, justicia/vida buena, etc., están y deben estar «abiertas a la controversia, la redefinición, la renegociación y la legitimación discursiva». Éste es el sentido central del concepto de religión pública que defiende Casanova: «Lo que yo llamo "desprivatización" de la religión moderna es el proceso por el cual la religión abandona su lugar asignado en la esfera privada y entra en la esfera pública indiferenciada de la sociedad civil para tomar parte en el proceso en curso de debate: la legitimación discursiva y el nuevo trazado de las fronteras» (Ibidem: 97). 


\section{Modalidades de intervención legítima de las «religiones públicas»}

\section{En sociedades no democráticas o autoritarias:}

Sería aquel tipo de intervención pública para proteger no sólo la propia libertad religiosa sino todas las libertades y derechos modernos. Es decir, la lucha, junto con otros movimientos de todo tipo, por la instauración de una sociedad civil democrática y, lo que es importante, sin buscar con ello la obtención de ningún tipo de privilegio o prerrogativa particulares para la propia religión.

\section{En las sociedades modernas democráticas:}

Aquí las religiones públicas podrían efectuar determinados tipos de intervención en el sentido de cuestionar y discutir legítimamente los límites del orden liberal social y político que las confina a la privacidad.

2.1. Intervención pública para proteger el mundo de la vida (por ejemplo, las formas de vida tradicionales: familia, modelos de comportamiento sexual, etc.) de la penetración administrativa o jurídica. Siempre y cuando se trate de un tipo de intervención en el terreno del debate público. Si se trata de un tipo de intervención tradicional antimoderna pondría en peligro el Estado liberal democrático, lo que no sería aceptable.

2.2. Desprivatización en el sentido de poner en cuestión o impugnar la absoluta autonomía de las esferas seculares, singularmente de los dos subsistemas sociales principales: el Estado y el mercado. Cuestionar que se rijan exclusivamente según sus propias normas funcionales intrínsecas, al margen de cualquier tipo de consideración ética o moral exteriores a tales esferas. Sería una contribución a la redefinición de las fronteras entre las esferas pública/privada, legalidad/moralidad, sistema/mundo de la vida, etc. Siempre que se efectúe en nombre de los derechos humanos o de valores humanos universales.

2.3. En relación con esto último estaría la pretensión de las religiones de mantener el principio del «bien común» en contra de las teorías liberales individualistas que tienden a reducirlo a la mera suma de las elecciones individuales. Serviría para recordar (junto a otras corrientes éticas o políticas) que debe existir una estructura normativa intersubjetiva (una dimensión social, institucional o estructural de la ética). O incluso para insistir, en plena época de globalización, que el «bien común» sólo puede definirse en términos universales, globales y humanos más allá de las fronteras nacionales o estatales. 
Ello exigiría obviamente a las religiones la aceptación plena de un pluralismo social y cultural tanto fuera, en la sociedad, como dentro de la propia institución religiosa. Y, por lo que respecta al catolicismo, al que se refiere especialmente Casanova, debería renunciar a seguir disfrutando de cualquier prerrogativa especial y, mucho más aún, a la pretensión de detentar el monopolio de la verdad en cualquier ámbito del que se trate al presentarse en la esfera pública, y asumir que su opinión es una más entre otras, que debe expresarse y hacerse valer en un lenguaje universalista y no particularista: «sea cual sea la postura o la opción que adopte», «la Iglesia tendrá que justificarla por medio de un discurso racional, público y abierto en la esfera pública de la sociedad civil» (Ibidem: 301).

Modelo normativo inaceptable para algunos, bien por exceso o bien por defecto, que es claramente compatible con una laicidad bien entendida, como se expresa, con gran claridad, en el relevante Informe de la Comisión Stasi sobre la Laicidad (11 diciembre 2003), elaborado en Francia para hacer frente a los nuevos desafíos planteados a la laicidad en unas sociedades crecientemente multiculturales y multirreligiosas.

«... lo espiritual y lo religioso deben prescindir de cualquier pretensión de dominio sobre el Estado y renunciar a su dimensión política. La laicidad es incompatible con cualquier concepción de la religión que deseara dirigir, en nombre de sus supuestos principios, el sistema social o el orden político.

En el marco laico, las opciones espirituales o religiosas dependen de la libertad individual: esto no significa en absoluto que estas cuestiones sean confinadas a la intimidad de la conciencia, "privatizadas", y que se les niegue cualquier dimensión social o capacidad de expresión pública. La laicidad distingue la libre expresión individual o religiosa en el espacio público, legítima y esencial en el debate democrático, del dominio sobre ese espacio, que es ilegítimo. Los representantes de las diferentes opciones espirituales están autorizados para intervenir a ese título en el debate público, como cualquier componente de la sociedad» (2003: 58).

En nuestras sociedades fuertemente pluralistas, el desafío es cómo forjar la unidad social respetando a un mismo tiempo su diversidad creciente. En este sentido, la laicidad representa los valores comunes de la sociedad, que se apoyan en una concepción de la ciudadanía que supera las pertenencias comunitarias, étnicas o confesionales. Por lo que el cristianismo puede y

${ }^{5}$ Es lo que defiende, por ejemplo, Javier Otaola desde su reflexión sobre la laicidad: «Sólo de una manera pudiera admitirse una cierta proyección de cualquier tipo de magisterio espiritual en el ámbito de la ciudad terrestre: cuando el discurso religioso puede traducirse al lenguaje de la razonabilidad del debate político, es decir, cuando no se funda ni se sostiene en ningún principio de fe o de revelación, sino que se apoya en una argumentación controvertible» (1999: 35-36). 
debe contribuir a fortalecer tal laicidad, en la medida en que se comporte realmente como «la religión de la salida de la religión».

«Ya no hay política cristiana posible. Hay una política profana, o "secular", o "laica", poco importa, en la que participan los cristianos con sus valores y convicciones, pero cuya última palabra no tienen [...]. La ética democrática no excluye nada, pero por eso mismo relativiza todas las posiciones. Rechaza la idea de que un componente de la colectividad pudiera poseer una verdad absoluta que impondría al conjunto. Es lo que la hizo antipática para los cristianos durante tanto tiempo. Ellos la denunciaban como una forma insoportable de relativismo y como una renuncia inaceptable a la idea de verdad. No hay nada de eso en realidad, pues el principio mismo de la libre discusión y de la igualdad de los interlocutores no tiene nada de relativo en la concepción democrática. Representa un absoluto. No implica ningún abandono de la verdad. La transforma desplazándola entre los interlocutores. Nadie la posee, pero todos participan en su búsqueda. Los cristianos pueden reconocerse en este absoluto democrático y en su comprensión de la verdad. Es lo que han hecho. La democracia les pide aceptar coexistir con no cristianos, admitiendo concederles una parte de verdad y admitiendo que el orden justo que unos y otros buscan construir será tanto el asunto de los no cristianos como el suyo» (GAUCHET, 2005b: 299).

Resuena en estas palabras, seguramente, un eco polémico frente a la postura de la jerarquía de la iglesia católica que tiende a identificar ciertas decisiones democráticas que no le gustan con un relativismo pernicioso y disolvente al no apoyarse en ciertas verdades absolutas, inscritas por Dios mismo en la naturaleza y de las que obviamente ella sería la única detentadora.

¿Será capaz la iglesia católica de superar estos resabios dogmáticos y colaborar con el resto de la sociedad, en igualdad de condiciones, a la construcción de una sociedad más justa?

«Por lo demás, ¿por qué excluir un aggiornamento en regla de las Iglesias extenuadas de nuestro Viejo Mundo que las liberaría de sus viejos demonios de autoridad; una conversión a la era democrática que les devolvería aliento y fuerza, permitiéndoles rehacer la base de la connivencia primera entre el espíritu del cristianismo y el destino occidental?» (Gauchet, 2005a: $\left.234-235^{6}\right)$.

\footnotetext{
${ }^{6}$ Gauchet, en consonancia con una concepción abierta de la laicidad -que frente a épocas pasadas o concepciones más estrechas, valora de forma positiva la aportación que las tradiciones religiosas pueden efectuar al «capital social» de las sociedades modernas-, y en la línea del planteamiento de Casanova, defiende la necesidad de que la tradición católica aporte los valores cristianos al debate de la esfera pública. Los valores católicos, escribe, «adquieren hoy todo su alcance polémico frente a las derivas del individualismo contemporáneo. [...]. Estos valores, provenientes de la religión cristiana, pero que tienen sentido para
} 


\section{Bibliografía citada}

BERGER, P. L. (1999/1967): El dosel sagrado. Para una teoría sociológica de la religión, Barcelona, Paidós.

Casanova, J. (2000/1994): Religiones públicas en el mundo moderno, Madrid, PPC.

«Dios vuelve a la política» (2006): Foreign Policy. Política, economía e ideas globales. Edición española, n. ${ }^{\circ} 16$, agosto-septiembre.

GAUChET, M. (2005a/1985): El desencantamiento del mundo. Una historia política de la religión, Madrid, Trotta.

-, (2005b): «Lo religioso hoy (Conversación con Esteban Molina)» El desencantamiento del mundo. Una historia política de la religión, Madrid, Trotta, pp. 293-302.

HALLIDAY, F. (1994): «El fundamentalismo y el mundo contemporáneo», Papeles de Cuestiones Internacionales, CIP, Madrid, n. ${ }^{\circ}$ 52, pp. 37-51.

KePEl, G. (1994): «Entrevista», El País («Temas de Nuestra Época»), 28 abril, p. 3.

-, (1995a/1991): La revancha de Dios. Cristianos, judíos y musulmanes a la reconquista del mundo, Madrid, Anaya \& Mario Muchnik.

KePel, G. (dir.) (1995b): Las políticas de Dios, Madrid, Anaya \& Mario Muchnik.

LAWRENCE, B. B. (1989): Defenders of God: the fundamentalist revolt against the modern age, New York, Harper and Row.

LUCKMANN, T. (1973/1967), La religión invisible. El problema de la religión en la sociedad moderna, Salamanca, Sígueme.

Michel, P. (1994): Politique et religion. La grande mutation, Paris, Albin Michel.

Otaola, J. (1999): Laicidad. Una estrategia para la libertad, Barcelona, Bellaterra.

Shah, T. S. y Duffy ToFt, M. (2006): «Por qué Dios está ganando», Foreign Policy. Política, economía e ideas globales. Edición española, n. ${ }^{\circ}$ 16, agosto-septiembre, pp. 22-28.

los que están fuera de la religión se resumen en una palabra: humanismo. [...] es del interés de una sociedad salida de la religión que existan en su seno instituciones religiosas vivas -naturalmente hablo de instituciones que han comprendido lo que significa democracia y que participan en el juego de la libertad humana-» (GAUCHET, 2005b: 301). Y señala tres aspectos de interés: 1. Desde el punto de vista de la identidad histórica, pues Europa sale del cristianismo. 2. Desde el punto de vista del debate colectivo, pues puede contribuir a recordar que más allá de lo trivial están los fines últimos. 3. Y desde la idea del hombre que puede aportar. Para concluir que: «La preocupación espiritual es incluso esencial a la idea más laica o más secular del hombre. A este respecto, el apoyo de la exigencia religiosa le es infinitamente precioso, desde el momento en que las religiones no pretenden constituir la ley de la sociedad» (Ibidem: 302). 
SutTer, J. (1991): «Quelle revanche de Dieu?», Esprit, octubre, pp. 116128.

Swatos, Jr., W. H. (ed.) (1989): Religious politics in global and comparative perspective, New York, Greenwood Press.

URRUTIA LEÓN, M. M. ${ }^{\text {a }}$ (2005): «Del concepto al paradigma de la secularización», Estudios de Deusto, vol. 53/1, enero-junio, pp. 163-181.

VV.AA. (2005): «Informe de la Comisión Stasi sobre la Laicidad (11 diciembre 2003)», Pasajes de Pensamiento Contemporáneo, Valencia, 18, otoño, pp. 57-73.

WuthNOw, R. (1992): Rediscovering the sacred. Perspectives on religion in contemporary society, Michigan, Eerdmans. 